\title{
Metabolic Studies of Carnitine in a Child with Propionic Acidemia
}

\author{
THADDEUS W. KURCZYNSKI, CHARLES L. HOPPEL, PETER J. GOLDBLATT, AND \\ WILLIAM T. GUNNING
}

\begin{abstract}
Departments of Pediatrics, Neurology, and Obstetrics/Gynecology, Medical College of Ohio, Toledo, OH 43699
[T.W.K.]; Veterans Administration Medical Center, Departments of Medicine and Pharmacology, Case Western Reserve University, Cleveland, Ohio 44106 [C.L.H.]; Department of Pathology, Medical College of Ohio, Toledo, Ohio 43699 [P.J.G., W.T.G.]
\end{abstract}

\begin{abstract}
Carnitine metabolism was studied in a 7-yold boy with propionic acidemia due to an almost total deficiency of propionyl-CoA carboxylase. The initial diagnosis was made at 3 wk of age followed by numerous episodes of metabolic acidosis despite a low-content branch-chain amino acid diet containing supplemental biotin. Although clinically stable and in a nonacidotic state, the plasma concentration of total carnitine was normal $(38.9 \mu \mathrm{M}$; normal $=46 \pm 10$, mean $\pm \mathrm{SD}, n=30)$ whereas free carnitine was decreased $(5.7 \mu \mathrm{M}$; normal $=37 \pm 8)$ and short-chain acylcarnitines were increased $(28.6 \mu \mathrm{M}$; normal $=5.7 \pm 3.5$ ). Skeletal muscle and liver specimens obtained at open biopsy had low total and free carnitine contents and increased ratio of short-chain acylcarnitines to free carnitine. Short-chain acylcarnitine content was low in liver but increased in skeletal muscle. The liver contained fatty vacuoles, enlarged mitochondria with paracrystalline inclusions, and numerous peroxisomes whereas the skeletal muscle also had lipid vacuoles and an increase in number and size of mitochondria. A carnitine challenge test $(100$ $\mathrm{mg}$ L-carnitine/ $\mathrm{kg}$ body wt via a gastrostomy tube) resulted in a peak plasma carnitine concentration at $120 \mathrm{~min}$. With maintenance therapy of $100 \mathrm{mg} \mathrm{L}$-carnitine/ $\mathrm{kg} / \mathrm{day}$ the plasma free carnitine remained relatively low, the plasma glycine concentration decreased, and urinary acylcarnitine excretion increased. This study demonstrates that the alterations in carnitine and its derivatives observed in plasma and urine reflect the same type of altered distribution in tissue and provides further data on the effects of $L$-carnitine therapy. (Pediatr Res 26: 63-66, 1989)
\end{abstract}

Systemic carnitine insufficiency has been implied in patients with propionic aciduria and other primary disorders of organic acid metabolism based on measurement of carnitine and its derivatives in plasma and urine (1-9). These studies have provided some insight into the biochemical pathophysiology of these inborn errors of metabolism as well as a rationale for their treatment with L-carnitine.

Our report of a patient with propionic acidemia shows that plasma and urinary measurements of carnitine and acylcarnitines reflect tissue levels of carnitine compounds. It also provides additional evidence of a generalized disturbance in carnitine metabolism in organic acidurias that is amenable to carnitine therapy.

Received August 15, 1988; accepted March 3, 1989.

Correspondence to Thaddeus W. Kurczynski, M.D., Ph.D., Department of Pediatrics, Medical College of Ohio, C.S. 10008, Toledo, OH 43699.

\section{CASE HISTORY}

The patient was a 7-y-old boy with propionic acidemia due to an almost complete absence of propionyl-CoA carboxylase activity. He presented at 10 days of age with hyperammonemia and metabolic acidosis and was treated with peritoneal dialysis. Plasma and urinary glycine were elevated, and urinary organic acid analysis demonstrated prominent excretion of propionic acid metabolites, including methylcitrate. The enzymatic diagnosis was established in cultured fibroblasts in the laboratory of Dr. L. Sweetman, University of California, San Diego, and there was no clinical response to biotin therapy.

He subsequently had numerous episodes of metabolic acidosis and by 2 y of age exhibited an aversion to oral feedings necessitating a feeding gastrostomy. The frequency of serious episodes of metabolic acidosis was eventually reduced with dietary management which included a restricted branched-chain amino acid intake using formula S-14 (Wyeth Laboratories, Philadelphia, PA) supplemented with polycose and bicarbonate. This provided $1 \mathrm{~g}$ of protein $/ \mathrm{kg} / \mathrm{day}$. Although relatively normal growth was maintained, little speech development occurred, and the patient was severely retarded.

The family history includes two normal siblings. The father has a history of seizures, and the patient had febrile seizures unrelated to metabolic acidosis.

At 6 y of age, the patient was referred to the Medical College of Ohio for follow-up care. Examination showed an alert, pleasant, non-verbal boy with a head circumference of $49.5 \mathrm{~cm}$ (10th percentile), wt $20.3 \mathrm{~kg}$ (50th percentile), and height $105.4 \mathrm{~cm}$ (less than the 5 th percentile). Significant findings on examination included mild coarsening of facial features, a liver palpable $5 \mathrm{~cm}$ below the right costal margin, the presence of a gastrostomy tube, and mild generalized hypotonia without any functional motor disability. Baseline laboratory studies included normal blood counts and chemistries except for a low blood urea nitrogen (4-10\%), mildly elevated SGOT (43-65 U/liter), and mildly elevated ammonia $(46 \mu \mathrm{M})$. A CT scan of the head showed an increased ventricular size. The electroencephalogram demonstrated nonspecific slowing.

With informed consent from the family, he was entered into a protocol approved by the institutional Review Board (Medical College of Ohio) for studying the treatment of organic acidurias with L-carnitine. The protocol involved periodic follow-up with determinations of plasma carnitine, blood counts, routine blood chemistries, amino acids, and urinary organic acids. The Lcarnitine was provided by American McGaw, Santa Ana, CA.

\section{MATERIALS AND METHODS}

Carnitine determinations were performed as previously described (6). Amino acid concentrations were obtained with an 
LKB4400 amino acid analyzer. Urinary organic acids were analyzed by a Hewlett-Packard gas chromatograph model 5840 and mass spectrometer model 5985 (Hewlett-Packard Co., Palo Alto, CA) after extraction of the urinary organic acids with ether/ethyl acetate (9). Relative concentrations of various organic acids were determined by comparing peak ratios with a 24 -carbon alkane internal standard. The data were analyzed by Student's $t$-test.

\section{RESULTS}

A liver biopsy demonstrated fatty changes on light microscopy, whereas electron microscopic examination showed many enlarged mitochondria with paracrystalline inclusions, and an abundance of microbodies (Fig. 1 and 2). A rectus abdominus muscle specimen demonstrated some variation in fiber size with an increase in the number and size of mitochondria as well as prominent lipid vacuoles on electron microscopy (Fig. 2).

The data for carnitine concentrations, in plasma and urine before and during daily administration of L-carnitine are presented in Table 1 and Figures 3 and 4. Table 2 shows tissue carnitine concentrations.

Before therapy. The plasma concentration of total carnitine and the urinary excretion of total carnitine were normal (Table 1). The plasma free carnitine concentration was decreased whereas the plasma short-chain acylcarnitines were increased. The urinary excretion of free carnitine was low whereas that of the acylcarnitines was within control limits. The content of carnitine and its derivatives in liver and skeletal muscle are shown in Table 2 . The total carnitine in liver is low ( $28 \%$ of the mean control value) although that in skeletal muscle was $68 \%$ of the mean. The free carnitine content was low in the liver $(12 \%)$ and skeletal muscle $(18 \%)$. Short-chain acylcarnitines were $43 \%$ of the mean in liver whereas they were increased 2-fold in skeletal muscle. Thus free carnitine was low in plasma, liver, skeletal muscle, and urine whereas the short-chain acylcarnitine content was increased in plasma and skeletal muscle but de- creased in liver. The ratio of acylcarnitine to carnitine was increased in tissues, plasma, and urine.

Before treatment the plasma glycine concentration was elevated $(1122 \mu \mathrm{mol} /$ liter $)$ and urinary organic acids showed the typical elevations of the 3-hydroxypropionate, $\mathrm{N}$-propionylglycine, and methylcitrate observed in propionic acidemia.

Posttherapeutic administration of $L$-carnitine. A challenge dose of $100 \mathrm{mg} \mathrm{L}$-carnitine/ $\mathrm{kg}$ body wt was given via gastrostomy tube. As shown in Figure 3, an increase in plasma carnitine followed this first dose reaching a maximum at $2 \mathrm{~h}$ followed by a gradual decline to stable level by 6-8 h. Maintenance dosing of $100 \mathrm{mg} \mathrm{L}$-carnitine/ $\mathrm{kg}$ body wt/day started $24 \mathrm{~h}$ after the first dose and was given mixed with the daily S-14 formula. The total and free carnitine were increased at 15 days of therapy compared to pretreatment values. After 8 mo of therapy, the total carnitine was decreased compared to that observed at 15 days. At this dose, the free carnitine never increased to the values observed in untreated control subjects. The short-chain acylcarnitine fraction, which was abnormally high before therapy, increased about 2 -fold more and remained at these levels throughout treatment.

The urinary excretion of carnitine increased during the first 2 days of therapy; the increase was predominantly acylcarnitines. A further increase in acylcarnitine occurred on the 3rd day whereas free carnitine excretion now showed an increase. The excretion of acylcarnitine was about $6 \mu \mathrm{mol} / \mathrm{mg}$ creatinine at 3 , 15 , and 68 days of treatment. The fluctuations observed in total carnitine excretion on these days were owing to changes in free carnitine excretion.

Over the period of observation after carnitine treatment, the plasma glycine concentration at day 68 was $620 \mu \mathrm{mol} /$ liter, onehalf that observed before carnitine therapy but was still not normal. The excretion of organic acids showed a decrease in lactate excretion with a gradual decrease in propionylglycine. In contrast, 3-hydroxypropionate and methylcitrate showed an initial increase followed by a decline but with persistent excretion. The excretion of hippurate increased markedly on the 1st day of treatment but subsequently decreased.

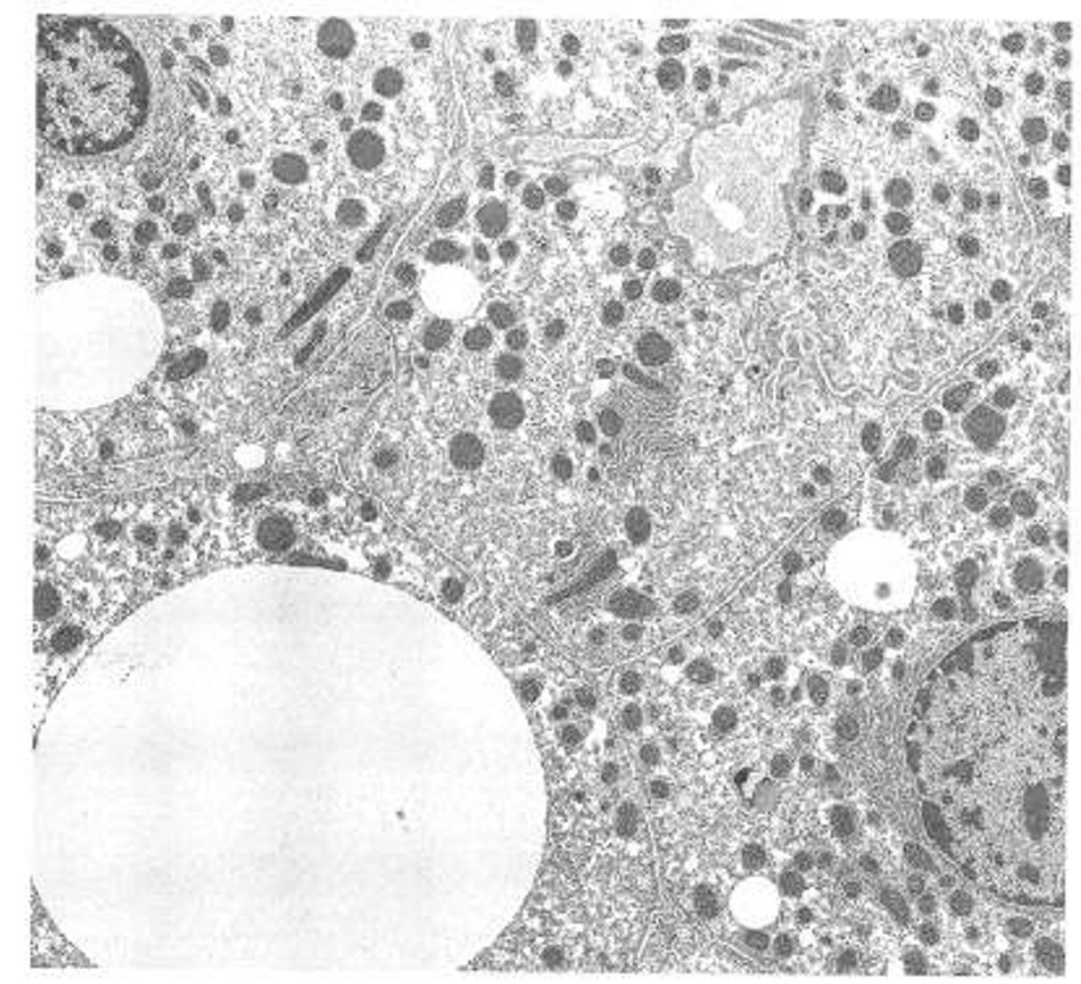

Fig. 1. Higher magnification electron micrograph of hepatocyte cytoplasm adjacent to nucleus (lefi) with clumped chromatin. Mitochondria at upper left show paracrystalline arrays and dense granules in the matrix. Numerous microbodies (peroxisomes) are scattered in the cytoplasm and some (center) have a dense nucleoid. However, this density does not have the characteristic substructure of crystalline uricase that has been described in species such as the rat which normally oxidize uric acid. Magnification 14,000×. 


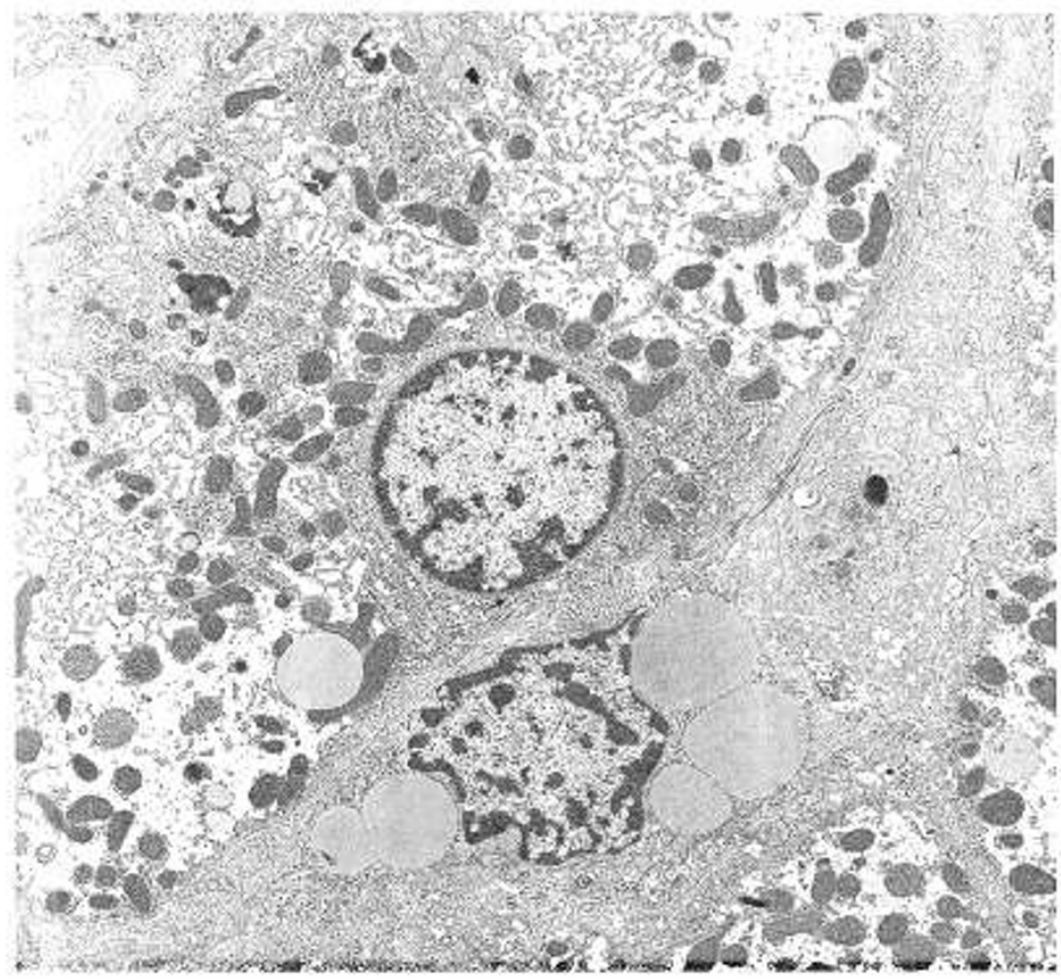

Fig. 2. Electron micrograph of muscle cell cytoplasm. The characteristic banding and myofibriller structure appears preserved. Between myofibers there appear to be increased members of lipid droplets in close approximations to mitochondria which also appear increased in number and have a more convoluted outline, some times enwrapping each other (upper left). Magnification $9000 \times$.

Table 1. Plasma and urine carnitine before treatment with L-carnitine

\begin{tabular}{|c|c|c|c|c|c|}
\hline Plasma & $\begin{array}{c}\text { Total } \\
\text { carnitine }\end{array}$ & $\begin{array}{c}\text { Free } \\
\text { carnitine }\end{array}$ & $\begin{array}{l}\text { Short-chain } \\
\text { acylcarnitine }\end{array}$ & $\begin{array}{c}\text { Long-chain } \\
\text { acylcarnitine }\end{array}$ & $\begin{array}{c}\text { Ratio } \\
\text { Short-chain/free }\end{array}$ \\
\hline \multicolumn{6}{|c|}{$\mu \mathrm{mol} / \mathrm{liter}$} \\
\hline Patient & 38.9 & $5.7^{*}$ & $28.6^{*}$ & 4.6 & $5.0^{*}$ \\
\hline Controls $(n=30)$ & $46 \pm 10$ & $37 \pm 8$ & $5.7 \pm 3.5$ & $3.7 \pm 1.5$ & $0.16 \pm 0.09$ \\
\hline Urine & $\begin{array}{c}\text { Total } \\
\text { carnitine }\end{array}$ & $\begin{array}{c}\text { Free } \\
\text { carnitine }\end{array}$ & & Acylcarnitine & $\begin{array}{c}\text { Ratio } \\
\text { acylcarnitine/free } \\
\text { carnitine }\end{array}$ \\
\hline \multicolumn{6}{|c|}{$\mu \mathrm{mol} / \mathrm{g}$ creatinine } \\
\hline Patient & 98.7 & $2.7 \dagger$ & & 96.0 & $35.6^{*}$ \\
\hline Controls $(n=10)$ & $125 \pm 75$ & $51 \pm 40$ & & $74 \pm 40$ & $1.97 \pm 1.15$ \\
\hline
\end{tabular}

$* p<0.001 ; \dagger p<0.05$; when compared to controls.

Table 2. Liver and muscle carnitine before treatment with L-carnitine*

\begin{tabular}{|c|c|c|c|c|c|}
\hline & $\begin{array}{c}\text { Total } \\
\text { carnitine }\end{array}$ & $\begin{array}{c}\text { Free } \\
\text { carnitine }\end{array}$ & $\begin{array}{l}\text { Short-chain } \\
\text { acylcarnitine }\end{array}$ & $\begin{array}{l}\text { Long-chain } \\
\text { acylcarnitine }\end{array}$ & $\begin{array}{c}\text { Ratio } \\
\text { short-chain } \\
\text { acylcarnitine/free } \\
\text { carnitine }\end{array}$ \\
\hline & \multicolumn{5}{|c|}{$\mu \mathrm{mol} / \mathrm{g}$ wet $w t$} \\
\hline \multicolumn{6}{|l|}{ Liver } \\
\hline Patient & $0.23 \dagger$ & $0.05 \dagger$ & 0.16 & $0.01 \dagger$ & $3.2 \dagger$ \\
\hline Normals & $0.83 \pm 0.26$ & $0.41 \pm 0.17$ & $0.37 \pm 0.20$ & $0.05 \pm 0.02$ & $1.14 \pm 0.97$ \\
\hline (Range) & $(0.65-1.29)$ & $(0.16-0.46)$ & $(0.16 \pm 0.44)$ & $(0.02 \pm 0.06)$ & $(0.35-2.75)$ \\
\hline \multicolumn{6}{|l|}{ Muscle } \\
\hline Patient & 1.56 & $0.29 \ddagger$ & $1.16 \ddagger$ & 0.11 & $4.0 \S$ \\
\hline Normals & $2.29 \pm 0.75$ & $1.62-0.67$ & $0.58 \pm 0.32$ & $0.09 \pm 0.03$ & $0.42 \pm 0.26$ \\
\hline (Range) & $(1.04-3.03)$ & $(0.60-2.16)$ & $(0.21-0.95)$ & $(0.05-0.14)$ & $(0.10-0.74)$ \\
\hline
\end{tabular}

* Liver and muscle (rectus abdominus) control biopsy data obtained from five infants with myopathy or cardiomyopathy and normal plasma carnitine, mean \pm SD (D. S. Kerr, and C. L. Hoppel, unpublished data).

$\dagger p<0.01$

$\ddagger p<0.05$.

$\S p<0.001$. 


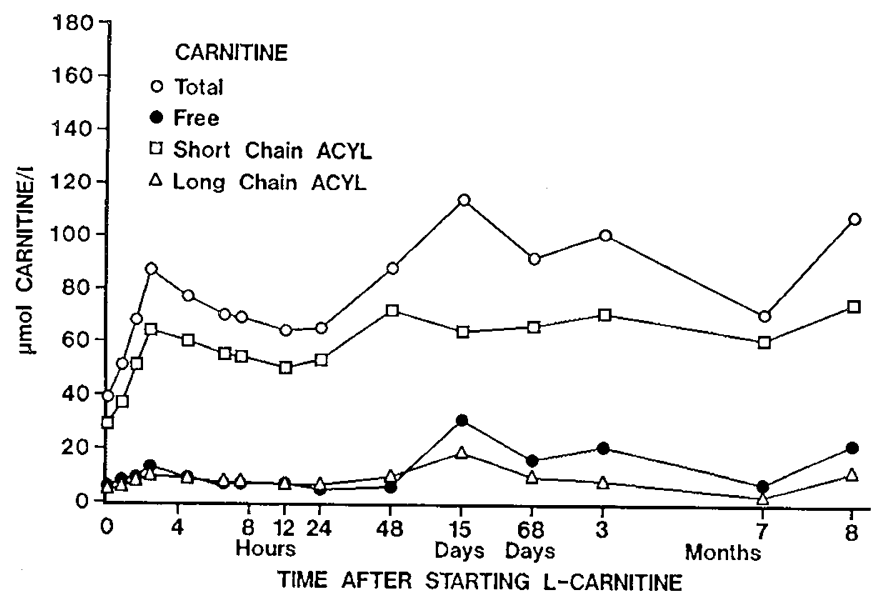

Fig. 3. Plasma carnitine after treatment with L-carnitine.

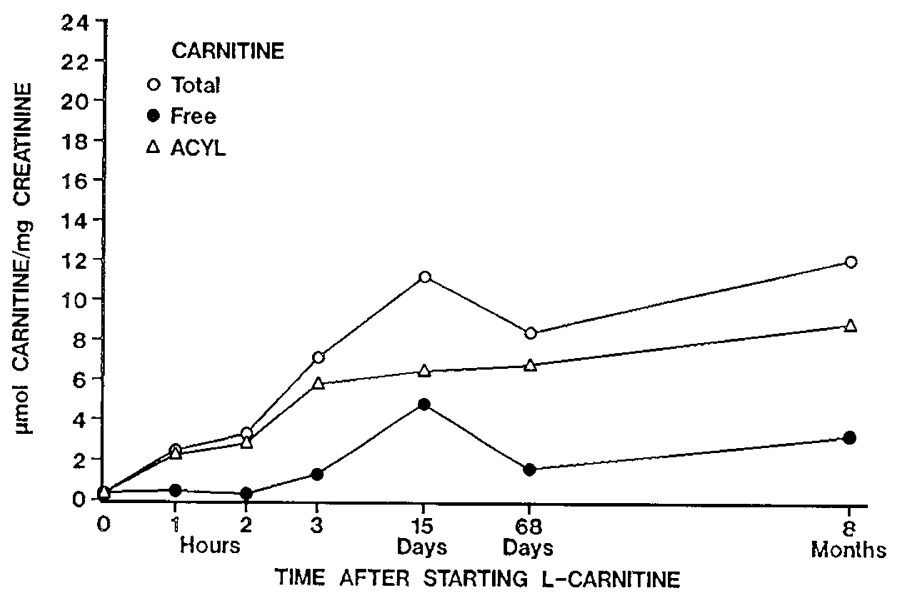

Fig. 4. Urine carnitine after treatment with L-carnitine.

\section{DISCUSSION}

The data presented are consistent with previous studies of plasma concentrations and urinary excretion of carnitine in propionic acidemia showing a decrease in free carnitine and an increase in acylcarnitines (2-5). In one patient, a skeletal muscle specimen showed a decrease in total, free, short-chain acyl- and long-chain acylcarnitines (2). In our patients, the plasma low free carnitine concentration and increased short-chain acylcarnitine reflect muscle carnitine, whereas in liver, both were low. The ratio of acylcarnitine to carnitine was elevated in plasma, urine, liver, and muscle. No other reports of liver carnitine fractions from patients with primary organic acidurias are available for comparison.

Treatment with $100 \mathrm{mg} / \mathrm{kg}$ of L-carnitine/day increased values of both total carnitine and acylcarnitines in plasma and urine, but the free plasma carnitine remained low despite 68 days of treatment. Similar observations of low free plasma carnitine were made by DiDonata et al. (2) in two patients treated with a lowprotein diet and $200 \mathrm{mg} / \mathrm{kg}$ L-carnitine/day and by Sugiyama et al. (4) who treated a patient with $80 \mathrm{mg} / \mathrm{kg}$ of DL-carnitine/day and protein restriction. Roe et al. (1) studied a patient with methylmalonic aciduria and found a normal plasma free carnitine after a single dose of $200 \mathrm{mg}$ DL-carnitine $/ \mathrm{kg}$. DiDonata et al. (2) treated two patients with methylmalonic acidemia with protein restriction and $200 \mathrm{mg}$ L-carnitine $/ \mathrm{kg}$ and found relatively normal free plasma carnitine levels. These data suggest a possible difference between propionic acidemia and methylmalonic acidemia in terms of the effect of carnitine supplementation on free plasma carnitine levels. Further studies will be needed to assess optimum dose and clinical response to prolonged carnitine treatment.
Chalmers et al. (5) have proposed that carnitine may be important in the treatment of organic acidurias by the removal of accumulated and potentially toxic acyl groups from the mitochondrion and cell as acylcarnitine esters. This would complement the important role of carnitine in the transport of longchain fatty acids into the mitochondrion for $\beta$-oxidation. Roe et al. (1), DiDonata et al. (2), and Chalmers et al. (3) have shown that the major urinary acylcarnitine in both methylmalonic and propionic acidemia is propionylcarnitine which is formed as a result of excess propionyl-CoA in both disorders. The urinary carnitine in the form of propionylcarnitine reflects the tissue values of the respective carnitine fractions and the disturbed mass action effect. This may then lead to secondary carnitine insufficiency which may be at least partially corrected by carnitine treatment.

The observed mitochondrial alterations in liver and muscle may be a reflection of the carnitine insufficiency. Mitochondrial changes have also been described in hyperammonemic patients with urea cycle abnormalities and Reye syndrome (10-12). Hyperammonemia per se, however, is not the likely primary cause of mitochondrial abnormalities because no mitochondrial changes were found in other reported patients with severe hyperammonemia and various urea cycle defects $(13,14)$. In addition, the presence of numerous microbodies (peroxisomes) in the liver may be a compensatory response to carnitine insufficiency, and this would be of interest to evaluate further in patients treated with carnitine. Increased microbodies have also been noted in patients with ornithine transcarbamylase deficiency $(10-11)$ where carnitine deficiency has been found (15) (Latham PS, LeBrecque DR, McReynolds JW, Klatskin G, unpublished data). The significance of low plasma free carnitine in propionic acidemia despite administration of pharmacologic doses of carnitine will require further evaluation.

\section{REFERENCES}

1. Roe CR, Hoppel CL, Stacey TE, Chalmers RA, Tracey BM, Mellington DS 1983 Metabolic response to carnitine in methylmalonic aciduria. Arch Dis Child 58:916-920

2. DiDonata S, Rimoldi M, Garavaglia B, Uziel G 1984 Propionylcarnitine excretion in propionic and methylmalonic acidurias: a case of carnitine deficiency. Clin Chim Acta 139:13-21

3. Chalmers RA, Roe CR, Stacey TE, Hoppel CL 1984 Urinary excretion of 1carnitine and acylcarnitines by patients with disorders of organic acid metabolism: evidence of secondary insufficiency of l-carnitine. Pediatr Res 18:1325-1328

4. Sugiyama N, Moroshita $H$, Nagaya S, Nakajima T, Kawase A, Ohya A, Sugiyama S, Kamiya K, Watanabe I, Togari H, Kobayashi M, Ogawa Y, Wada Y 1984 Biochemical evidence of carnitine effect on propionate elimination. J Inher Metab Dis 7:137-138

5. Chalmers RA, Stacey TE, Tracey BM, DeSousa C, Roe CR, Mellington DS, Hoppel CL 1984 L-carnitine insufficiency in disorders or organic acid metabolism: response to $\mathrm{L}$-carnitine by patients with methylmalonic aciduria and 3-hydroxy-3-methylglutaric aciduria. J Inherited Metab Dis 7:109-110

6. Brass EP, Hoppel CL 1978 Carnitine metabolism in the fasting rat. J Biol Chem 253:2688-2693

7. Hoppel CL, Genuth SM 1980 Carnitine metabolism in normal-weight and obese human subjects during fasting. Am J Physiol 238:E409-415

8. Genuth SM, Hoppel CL 1979 Plasma and urine carnitine in diabetic ketosis. Diabetes 28:1083-1087

9. Goodman SI, Markey SP 1981 Diagnosis of Organic Acidemias by Gas Chromatography-Mass Spectrometry. Alan R. Liss, Inc., New York

10. Shapiro JM, Schaffner F, Tallan HH, Gaull GE 1980 Mitochondrial abnormalities of liver in primary ornithine transcarbamylase deficiency. Pediatr Res 14:735-739

11. Zimmerman A, Bachmann C, Colombo JP 1981 Ultrastructural pathology in congenital defects of the urea cycle: ornithine transcarbamylase and carbamylphosphate synthetase deficiency. Virchows Arch [A] 393:321-331

12. Zimmerman, A, Bachmann C, Schubiger G 1985 Liver pathology in a new congenital disorder of urea synthesis: n-acetylglutamate synthetase deficiency. Virchows Arch [A] 408:259-268

13. LaBrecque DR,U Latham PS, Riely CA, Hsia YE, Klatskin G 1979 Heritable urea cycle enzyme deficiency-liver disease in 16 patients. J Pediatr 94:580587

14. Latham PS, LaBrecque DR, McReynolds JW, Klatskin G 1984 Liver ultrastructure in mitochondrial urea cycle enzyme deficiencies and comparison with Reye's syndrome. Hepatology 4:404-407

15. Ohtani Y, Ohyanagi K, Yamamoto S, Matsuda I 1988 Secondary carnitine deficiency in hyperammonemic attacks of ornithine transcarbamylase deficiency. J Pediatr 112:409-414 